\title{
ANALISIS PERTUMBUHAN PEMBIAYAAN UMKM TERHADAP PERTUMBUHAN LABA BERSIH BPRS DI INDONESIA
}

\author{
Mochamad Indrajit Roy \\ IAIN Sultan Maulana Hasanuddin Banten \\ Email: indrajit.roy@uinbanten.ac.id
}

\begin{abstract}
The Growth Analysis of UMKM Financing towards BPRS Net Income in Indonesia. The profit sharing of UMKM Financing may become additional profit for $B P R S$. Increasing the number of UMKM Financing will also increase the additional income of Islamic Financing Bank (BPRS) from the implemented profit sharing system. On the other hand, the growing number of financing will also increase the profit of BPRS. This study used the form of time series data from 2014 to November 2016. The growth of UMKM Financing as an independent variable, and growth Net profit. Data analysis was performed using simple regression analysis. After the classical assumption test, the analyzed data meets the criteria of classical assumptions. A simple regression analysis was performed, and from the results of hypothesis testing, showed a significance value of 0.013 is smaller than the value of $\alpha 0.05$. So the alternative hypothesis (Ha) is accepted. Therefore, it can be concluded that the growth of UMKM Financing has a significant effect on the growth of net profit of BPRS.
\end{abstract}

Keywords: Financing, Net Profit.

Abstrak. Analisis Pertumbuhan Pembiayaan UMKM Terhadap Pertumbuhan Laba Bersih BPRS di Indonesia. Bagi hasil dari Pembiayaan UMKM dapat menjadi tambahan Laba bagi BPRS. Meningkatnya jumlah Pembiayaan UMKM akan meningkatkan pula tambahan pendapatan atau penghasilan BPRS dari sistem Bagi Hasil yang dijalankan. Dengan kata lain, semakin bertumbuhnya jumlah Pembiayaan akan meningkatkan pula pertumbuhan Laba BPRS. Data yang digunakan berupa data deret waktu (time series) periode 2014 hingga November 2016. Data yang digunakan adalah pertumbuhan Pembiayaan UMKM sebagai variabel bebas, dan pertumbuhan Laba bersih. Analisis data yang dilakukan dengan menggunakan analisis regresi sederhana. Setelah dilakukan uji asumsi klasik, data yang dianalisis memenuhi kriteria asumsi klasik. Analisis regresi sederhana dilakukan, dan dari hasil uji hipotesis, menunjukkan nilai signifikansi sebesar 0,013 lebih kecil dari nilai $\alpha$ 0,05. Sehingga hipotesis alternatif (Ha) diterima. Maka dari itu dapat disimpulkan bahwa pertumbuhan Pembiayaan UMKM berpengaruh nyata terhadap pertumbuhan Laba bersih BPRS.

Kata Kunci: Pembiayaan, Laba bersih. 


\section{Pendahuluan}

Indonesia merupakan negara yang menerapkan sistem perekonomian campuran. Peranan pemerintah dan swasta sebagai pelaku ekonomi diperlukan sinergitas yang baik. Suatu negara memerlukan stimulasi yang dapat mendorong perkembangan dan pertumbuhan ekonomi. Program kewirausahaan yang dicanangkan oleh pemerintah diharapkan dapat menjadi stimulasi yang akan mendorong perkembangan dan pertumbuhan ekonomi. Dengan adanya program tersebut, membuat kegiatan usaha mikro kecil dan menengah (UMKM) berkembang. Secara makroekonomi, dengan berkembangya UMKM, akan terjadinya penambahan variasi produk dan menambah Produk Domestik Bruto (PDB). Hal tersebut secara langsung maupun tidak langsung dapat mendorong terjadinya perkembangan ekonomi, bahkan dapat pula mendorong pertumbuhan ekonomi. Selain itu, berkembangnya UMKM secara makroekonomi dapat mengurangi jumlah pengangguran, karena masyarakat yang sebelumnya berstatus pengangguran beranjak untuk melakukan kegiatan UMKM. Pada kegiatan UMKM, tidak hanya dilakukan oleh satu orang saja, tentunya dapat juga menarik para pengangguran lainnya untuk ikut membantu bekerja pada pemilik UMKM. Berkembangnya UMKM juga dapat meningkatkan tingkat kesejahteraan masyarakat, khususnya para pelaku usaha tersebut.

Perkembangan UMKM bukannya tidak ada kendala. Kendala yang umumnya dihadapi oleh para pelaku UMKM adalah keterbatasan modal usaha. Program Kredit Usaha Rakyat telah dicanangkan dan diselenggarakan oleh lembaga keuangan. Perbankan dan Perbankan syariah merupakan lembaga keuangan yang telah menerapkan program tersebut melalui produk-produknya. Adapun produk yang terkait dengan produk ini adalah produk Pembiayaan untuk UMKM dan Micro Finance. Sinergitas antara lembaga keuangan, pelaku usaha dan pemerintah diperlukan agar perkembangan UMKM dapat memberikan kontribusi terhadap Perekonomian.

Lembaga Keuangan seperti Perbankan dan Perbankan Syariah merupakan salah satu pilar dalam perekonomian makro. Dari sekian banyak Lembaga Keuangan, terdapat perbankan yang secara khusus melayani pembiayaan bagi masyarakat, 
Mochamad Indrajit Roy: Analisis Pertumbuhan...

khususnya masyarakat kecil dan menengah, yaitu Bank Pembiayaan Rakyat (BPR) dan Bank Pembiayaan Rakyat Syariah (BPRS).

BPR dan BPRS melakukan kegiatan utama menyelenggarakan program atau produk-produk pembiayaan bagi masyarakat. BPR dan BPRS secara umum merupakan Badan Usaha Milik Daerah (BUMD). BPR dan BPRS terdapat di seluruh wilayah Kota dan Kabupaten.

Perekonomian islam di Indonesia masih didominasi oleh lembaga keuangan yang menerapkan sistem syariah pada kegiatan bisnisnya. BPRS merupakan salah satu perbankan Syariah yang melakukan kegiatan bisnis berbasis syariah. Secara khusus, BPRS menerapkan kegiatan bisnisnya pada sektor riil. Pada perekonomian Indonesia, sektor riil dapat menyokong konsistensi dan kestabilan perekonomian suatu wilayah.

Secara mikroekonomi, BPRS sebagai salah satu pelaku ekonomi mikro, akan melakukan kegiatan bisnisnya dengan pertimbangan seberapa besar dapat menghasilkan keuntungan atau Laba. Karena setiap perusahaan pasti akan berorientasi terhadap laba, begitu pula dengan BPRS. Salah satu indikator penting yang dapat membuat pelaku ekonomi dapat terus bertahan dalam melakukan kegiatan bisnisnya adalah Laba. Para pengelola perusahaan dituntut pula agar dapat membuat Laba perusahaan secara kontinu meningkat.

Sesuai dengan namanya, Bank Pembiayaan Rakyat Syariah (BPRS) memberikan pembiayaan pada masyarakat. Kegiatan ini tidak hanya menjadi kegiatan utama, tetapi dapat memberikan kontribusi terhadap Laba perusahaan. Gambaran mengenai pembiayaan UMKM dan Laba BPRS dapat dilihat pada Tabel 1 berikut ini. 
Tabel 1. Jumlah Pembiayaan dan Laba Bersih BPRS Periode 2016 (Dalam Juta Rupiah)

\begin{tabular}{|c|c|c|c|c|c|}
\hline Tahun & Bulan & Laba Bersih & Pert. Laba & Pmbyn UMKM & $\begin{array}{l}\text { Pert. Pmbyn } \\
\text { UMKM }\end{array}$ \\
\hline \multirow{11}{*}{2016} & Januari & $\begin{array}{ll}\mathrm{Rp} & 6.460\end{array}$ & & $\mathrm{Rp} \quad 3.325 .863$ & \\
\hline & Februari & $\begin{array}{ll}\mathrm{Rp} & 17.410\end{array}$ & 169,51 & Rp 3.379 .218 & 1,60 \\
\hline & Maret & $\begin{array}{ll}\text { Rp } & 28.442\end{array}$ & 63,36 & Rp 3.444 .067 & 1,92 \\
\hline & April & $\begin{array}{ll}\mathrm{Rp} & 37.862\end{array}$ & 33,12 & Rp 3.546.255 & 2,97 \\
\hline & Mei & $\begin{array}{ll}\text { Rp } & 49.658\end{array}$ & 31,15 & Rp 3.651 .904 & 2,98 \\
\hline & Juni & Rp 71.774 & 44,54 & Rp 3.689 .925 & 1,04 \\
\hline & Juli & Rp 75.288 & 4,90 & Rp 3.632 .843 & $-1,55$ \\
\hline & Agustus & $\begin{array}{ll}\mathrm{Rp} & 83.486\end{array}$ & 10,89 & Rp 3.643 .769 & 0,30 \\
\hline & September & Rp 108.508 & 29,97 & Rp 3.473 .147 & $-4,68$ \\
\hline & Oktober & Rp 128.536 & 18,46 & Rp 3.467.101 & $-0,17$ \\
\hline & November & Rp 137.713 & 7,14 & Rp 3.498 .449 & 0,90 \\
\hline
\end{tabular}

Sumber: Statistik Perbankan Syariah (OJK)

Pada saat penulis melakukan penelitian ini, belum dipublikasikan data Statistik Perbankan Syariah bulan Desember. Sehingga data Tahun 2016 hanya diketahui hingga bulan November.

Bila diperhatikan secara umum, terjadi tren yang meningkat antara Laba bersih disertai dengan tingkat Pembiayaan UMKM selama Tahun 2016. Selain itu, terjadi pula adanya kenaikan Laba bersih yang tidak disertai dengan kenaikan Jumlah Pembiayaan UMKM. Dapat dilihat pada periode Juli, September dan Oktober, terjadi penurunan jumlah Pembiayaan UMKM tetapi tingkat Laba bersih mengalami peningkatan.

Sistem bagi hasil dari Pembiayaan dapat menjadi tambahan Laba bagi BPRS. Secara makroekonomi, dengan berkembangnya Pembiayaan akan meningkatkan pendapatan Negara dari sektor Pajak, baik dari PPh maupun PPN dari hasil produkproduk yang terjual. Sedangkan bila ditinjau secara perspektif mikroekonomi dari BPRS, dengan meningkatnya jumlah Pembiayaan, maka akan meningkatkan pula tambahan pendapatan atau penghasilan BPRS dari sistem Bagi Hasil yang dijalankan. 
Mochamad Indrajit Roy: Analisis Pertumbuhan...

Sehingga dapat dikatakan bahwa dengan semakin bertumbuhnya jumlah Pembiayaan akan meningkatkan pula pertumbuhan Laba BPRS.

Berdasarkan uraian latar belakang tersebut, peneliti ingin menganalisis dan membuktikan pengaruh pertumbuhan Pembiayaan UMKM terhadap pertumbuhan Laba bersih BPRS. Adapun perumusan masalah penelitian ini untuk mengetahui tingkat pengaruh pertumbuhan Pembiayaan UMKM terhadap pertumbuhan Laba BPRS di Indonesia. Dengan demikian dapat menganalisis tingkat pengaruh pertumbuhan Pembiayaan UMKM terhadap pertumbuhan Laba BPRS di Indonesia.

Dari uraian rumusan masalah, maka hipotesis penelitian ini adalah sebagai berikut:

Ho : Tidak terdapat pengaruh yang signifikan pertumbuhan Pembiayaan UMKM terhadap pertumbuhan Laba bersih BPRS di Indonesia.

Ha : Terdapat pengaruh yang signifikan pertumbuhan Pembiayaan UMKM terhadap pertumbuhan Laba bersih BPRS di Indonesia.

\section{Tinjauan Pustaka}

Diterangkan dalam Undang-Undang Nomor 21 Tahun 2008 Tentang Perbankan Syariah mengenai Pembiayaan. Pembiayaan adalah penyediaan dana atau tagihan yang dipersamakan dengan itu berupa:

a) Transaksi bagi hasil dalam bentuk Mudharabah dan Musyarakah;

b) Transaksi sewa-menyewa dalam bentuk ijarah atau sewa beli dalam bentuk ijarah muntahiya bitamlik;

c) Transaksi jual beli dalam bentuk piutang murabaha, salam, dan istishna;

d) Pinjam meminjam dalam bentuk piutang qardh, dan

e) Transaksi sewa-menyewa jasa dalam bentuk ijarah dalam transsaksi multijasa".

Sedangkan menurut Kasmir (2008), Pembiayaan adalah penyedia uang atau tagihan yang dipersamakan dengan itu atas persetujuan antar Bank dengan pihak lain yang mewajibkan pihak yang dibiayai untuk mengembalikan uang atau tagihan tersebut setelah jangka waktu tertentu dengan imbalan atau bagi hasil. 
Islamiconomic: Jurnal Ekonomi Islam

Vol.8 No.1 Januari - Juni 2017

Menurut Rustami dkk (2014), Laba adalah selisih antara seluruh pendapatan (revenue) dan beban (expense) yang terjadi dalam suatu periode akuntansi. Laba merupakan suatu kelebihan pendapatan atau keuntungan yang layak diterima oleh perusahaan, karena perusahaan tersebut telah melakukan pengorbanan untuk kepentingan lain pada jangka waktu tertentu dalam Rustami dkk (2014). Sedangkan menurut Simorangkir (2003), pertumbuhan Laba adalah perubahan persentase kenaikan laba yang diperoleh perusahaan.

Salah satu tujuan BPRS melakukan kegiatan Pembiayaan terhadap para pelaku UMKM adalah untuk memperoleh keuntungan dari bagi hasil usaha para pelaku UMKM. Menurut Kasmir (2008), pemberian Pembiayaan memiliki tujuan utama. Salah satu tujuan utama pemberian Pembiayaan adalah untuk mencari keuntungan. Keuntungan yang dalam hal ini berupa bagi hasil sangat penting bagi kelangsungan hidup Bank, terlebih lagi pada umumnya sebagian besar dana Bank dialokasikan pada pembiayaan sehingga menyumbangkan pendapatan besar.

\section{Metodologi}

\section{a. Waktu dan Jenis Penelitian}

Penelitian ini dilakukan pada bulan Desember 2016. Jenis penelitian ini adalah penelitian kuantitatif, dimana pengumpulan data, penafsiran terhadap data, serta penampilan dari hasilnya berupa angka. Penyajian hasil disertai dengan tabel, grafik, bagan, gambar atau tampilan lain.

\section{b. Data, Populasi, Sampel dan Teknik Sampling}

Penelitian ini menggunakan data deret waktu (Time Series). Populasi data pada penelitian ini adalah seluruh data Laba bersih dan jumlah Pembiayaan BPRS dari mulai awal berdiri hingga November 2016. Sedangkan sampel penelitian ini adalah data Laba dan Pembiayaan UMKM per-bulan mulai dari Januari 2014 hingga November 2016. Teknik sampling pada penelitian ini adalah Purposive Sampling, dimana penentuan sampel dilakukan dengan sengaja dan pertimbangan tertentu. 


\section{c. Teknik Analisis Data}

Analisis data statistik pada penelitian ini dilakukan dimulai dengan pengelompokan, perhitungan penyesuaian, dan kemudian hasil yang diperoleh ditulis dalam bentuk tabel, dipersiapkan untuk input komputer sesuai model yang digunakan. Proses pengolahan dan analisis data menggunakan program statistik SPSS for Windows.

Analisis regresi digunakan untuk mengetahui tingkat signifikansi antara variabel bebas dan variabel terikat. Analisis regresi dapat digunakan untuk membuat perkiraan nilai suatu variabel (variabel dependen) jika nilai variabel yang lain yang berhubungan dengannya (variabel independen) sudah ditentukan atau diketahui. Adapun model persamaan Regresi pada penelitian ini adalah regresi sederhana :

$$
\mathbf{Y}=\mathbf{a}+\mathbf{b} \mathbf{X}+\mathbf{e}
$$

Dimana :

$$
\begin{aligned}
& \mathrm{Y}=\text { Pertumbuhan Laba Bersih BPRS periode tertentu } \\
& \mathrm{a}=\text { Konstanta } \\
& \mathrm{b}=\text { Koefisien regresi dari Pembiayaan UMKM BPRS. } \\
& \mathrm{X}_{1}=\text { Pertumbuhan Pembiayaan UMKM BPRS } \\
& \mathrm{e}=\text { error term (faktor pengganggu). }
\end{aligned}
$$

\section{Uji Asumsi Klasik}

\section{a) Uji Normalitas}

Data yang digunakan dalam model persamaan regresi harus terdistribusi normal. Uji normalitas data dapat dilakukan dengan melihat histogram pada hasil output pengujian dengan menggunakan software statistik. Apabila data tidak terdistribusi normal maka diperlukan transformasi data. Menurut Ghozali (2011), "data yang tidak terdistribusi secara normal dapat ditransformasikan agar menjadi normal". Salah satu trasformasi data yang dapat dilakukan adalah dengan mentransformasikan data ke bentuk Ln. 


\section{b) Uji Multikolinearitas}

Menurut Ghozali (2011), secara sederhana mendiagnosis terhadap adanya multikolinearitas di dalam model regresi dengan melihat nilai VIF (Variance Inflation Factor) yang terdapat pada hasil outputnya. Nilai VIF yang lebih besar dari 10 mengindikasikan adanya gejala multikolinear.

\section{c) Uji Heteroskedastisitas}

Salah satu cara yang digunakan untuk mengetahui ada tidaknya gejala heteroskedastisitas adalah dengan melihat sebaran plot pada grafik scatter plot. Apabila sebaran titik data menyebar dan tidak membentuk pola, maka tidak ada masalah heteroskedastisitas. Menurut Ghozali (2011), uji heteroskedastisitas bertujuan menguji apakah dalam model regresi terdapat ketidaksamaan variance dari residual satu pengamatan ke pengamatan lain.

\section{d) Uji Autokorelasi}

Menurut Ghozali (2011) cara mendeteksi dilakukan dengan menggunakan uji Durbin Watson dengan ketentuan sebagai berikut :

$$
\begin{array}{ll}
0 \quad<\text { DW }<\text { dl } & \text { :Terjadi autokorelasi } \\
\text { dl }<\text { DW }<\text { du } & : \text { Tidak dapat disimpulkan } \\
\text { du }<\text { DW }<4 \text {-du } & \text { : Tidak ada autokorelasi } \\
\text { 4-du }<\text { DW }<4-\text { dl } & : \text { Tidak dapat disimpulkan } \\
\text { 4-dl }<\text { DW }<4 & : \text { Terjadi autokorelasi }
\end{array}
$$

\section{Uji Hipotesis}

Uji $\mathrm{t}$ digunakan untuk mengetahui pengaruh masing-masing variabel independen terhadap dependen, dalam Ghozali (2011). Dengan melihat dan menggunakan angka signifikansi :

Apabila angka signifikansi $<\alpha(0,1)$ maka $\mathrm{H}_{0}$ diterima.

Apabila angka signifikansi $>\alpha(0,1)$ maka $\mathrm{H}_{\mathrm{a}}$ diterima dan $\mathrm{H}_{0}$ ditolak. 


\section{Hasil dan Pembahasan}

\section{Uji Asumsi Klasik}

Pengujian asumsi klasik merupakan tahapan-tahapan yang dilakukan sebelum data dianalisis. Adapun hasil pengujian asumsi klasik antara lain :

\section{a. Uji Normalitas}

Uji normalitas data dapat dilihat dari hasil gambar histogram berikut ini :

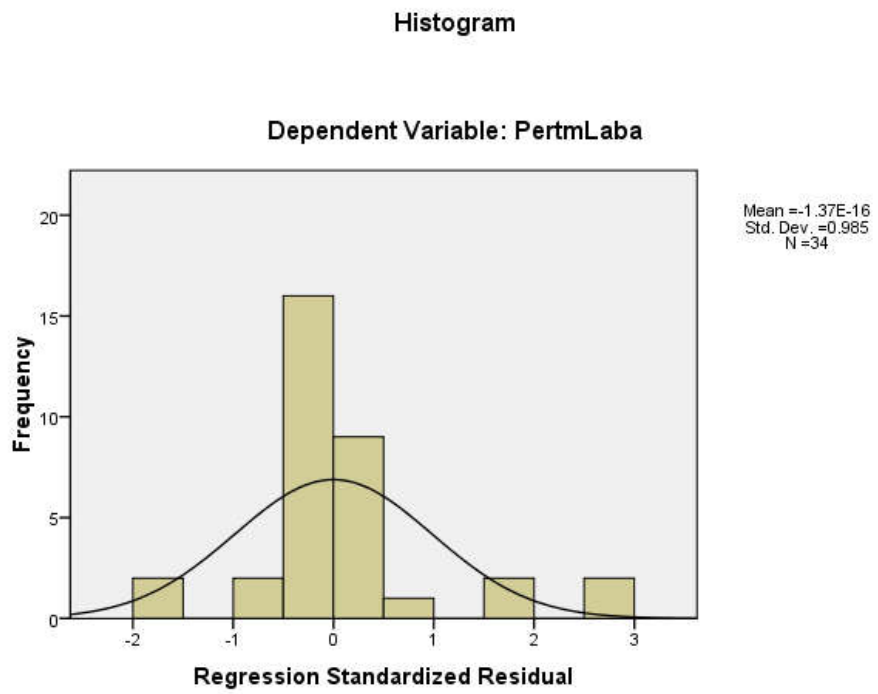

Dari histogram di atas, dapat dilihat bahwa sebaran data terdistribusi normal. Sehingga asumsi klasik untuk normalitas data telah terpenuhi.

\section{b. Uji Multikolinearitas}

Nilai VIF digunakan untuk meihat apakah tedapat masalah multikolinearitas atau tidak.

Tabel 4. Nilai VIF

\begin{tabular}{|l|l|}
\hline Variabel & Nilai VIF \\
\hline Pertumbuhan Biaya Promosi & 1.00 \\
\hline
\end{tabular}

Nilai VIF yang diperoleh 1,00 lebih kecil dari 10,00. Dengan demikian syarat asumsi klasik untu multikolinearitas dapat terpenuhi, dimana tidak terdapat masalah multikolinearitas. 


\section{c. Uji Heteroskedastisitas}

Uji ini dapat dilakukan dengan cara melihat gambar grafik Scatterplot berikut ini :

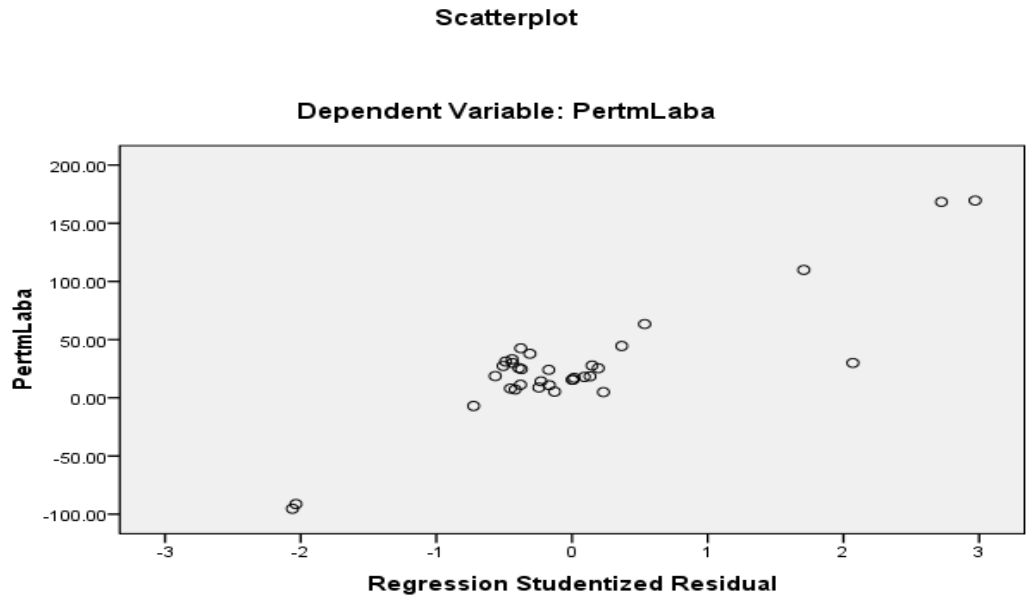

Dilihat dari diagram Scatterplot tersebut, tidak terbentuk pola dari sebaran plot. Sehingga dapat disimpulkan bahwa model persamaan tidak terdapat masalah Heteroskedastisitas.

\section{d. Uji Autokorelasi}

Berdasarkan hasil analisis, nilai DW diperoleh 2.270. Bila dibandingkan dengan Nilai D tabel dimana $\mathrm{T}=34 ; \mathrm{k}=1$; dengan $\alpha=0.05$, diperoleh nilai $\mathrm{du}=1,2837$ dan nilai $\mathrm{dl}=1,5666$ Jadi nilai DW hitung terletak pada : du $<$ DW $<4$-du. Dengan demikian model tersebut tidak terdapat masalah autokorelasi.

Dari hasil perhitungan dengan menggunakan bantuan program komputer SPSS for windows maka dapat diperoleh hasil perhitungan sebagai berikut:

Tabel 4. Hasil Uji Regresi

\begin{tabular}{|l|c|r|r|}
\hline Variabel & Unstandardized & \multicolumn{1}{l|}{ t hitung } & \multicolumn{1}{l|}{ Sig. } \\
\hline Constant & Coefficients (B) & & \\
\hline Pert. Pembiayaan UMKM (X) & 14,643 & 1,618 & 0,116 \\
\hline
\end{tabular}


Mochamad Indrajit Roy: Analisis Pertumbuhan...

$\begin{aligned} \text { R Square } & =0,179 \quad(17,9 \%) \\ \text { R Square }(\text { Adj }) & =0,153 \quad(15,3 \%) \\ \text { F hitung } & =6,978 \\ \text { Sig. } & =0,013 \\ \alpha & =0,05 \quad(5 \%)\end{aligned}$

- Dependen variabel : Pertumbuhan Laba Bersih

Dari nilai konstanta dan koefisien variabel, maka dapat dibuat model regresi berganda adalah sebagai berikut :

\begin{tabular}{|c|c|c|c|}
\hline Pertumbuhan & $=14,643$ & $\begin{array}{r}12,80 \\
+\end{array}$ & (Pertumbuhan \\
\hline Laba & & 5 & Pembiayaan UMKM) \\
\hline
\end{tabular}

\section{Pembahasan}

Hasil perhitungan dan analisis regresi, terdapat nilai koefisien determinasi $(R$ Square) sebesar 0,179. Artinya pertumbuhan Pembiayaan UMKM dapat menjelaskan 17,9 persen model pertumbuhan Laba.

Nilai koefisien variabel bebas bernilai positif. Hal ini menunjukkan bahwa bila pertumbuhan Pembiayaan UMKM naik (Positif), maka variabel pertumbuhan Laba akan naik pula. Nilai koefisien pertumbuhan Pembiayaan UMKM sebesar 12,805. Dapat diintrepretasikan bila setiap ada perubahan tingkat pertumbuhan Pembiayaan UMKM sebesar satu satuan, maka tingkat pertumbuhan Laba akan berubah sebesar 12,805 satuan.

Dari uji hipotesis hasil menggunakan uji t, pada variabel pertumbuhan Pembiayaan UMKM, nilai Sig. 0,013 lebih kecil dibanding nilai $\alpha$ 0,05. Sehingga dapat diinterpretasikan bahwa pertumbuhan Pembiayaan UMKM memiliki pengaruh yang signifikan terhadap tingkat pertumbuhan Laba. 


\section{Kesimpulan}

Kesimpulan yang dapat diambil dari hasil penelitian ini adalah sebagai berikut:

1) Pertumbuhan Pembiayaan UMKM memiliki pengaruh yang signifikan terhadap tingkat pertumbuhan Laba BPRS di Indonesia.

2) Pertumbuhan Pembiyaan UMKM memiliki kontribusi secara positif terhadap laju pertumbuhan Laba bersih BPRS.

\section{Daftar Pustaka}

Ghozali, Imam. 2011. Aplikasi Analisis Multivariate dengan Program SPSS. Badan Penerbit Universitas Diponegoro, Semarang.

Kasmir. 2008. Bank dan Lembaga Keuangan Lainnya. Edisi Revisi. PT. Rajagrapindo Persada. Jakarta.

Rustami, Putu dkk. 2014. Pengaruh Biaya Produksi, Biaya Promosi, Dan Volume Penjualan Terhadap Laba: Pada Perusahaan Kopi Bubuk Banyuatis. e-Journal Bisma Universitas Pendidikan Ganesha Jurusan Manajemen Vol 2.

Simorangkir, O. P. 2003. Etika : Bisnis, Jabatan, dan Perbankan. Rineka Cipta. Jakarta.

Undang-Undang Nomor 21 Tahun 2008 Tentang Perbankan Syariah. 